\title{
Practice of Teaching Reform of Combining University Sports Class and Sunshine Sports Feiquan Liu, Tao Yang
}

School of General Education, Qingdao University of Technology, Jiaozhou, 266300, China

Keywords: University sports class; sunshine sports; teaching reform practice

\begin{abstract}
This paper is mainly to research how to reform teaching and promote the healthy development of commemoratory university students in the context of "sunshine sports". The teaching strategy of entry of sunshine sports into the sports class of universities proposed by the Ministry of Education has some proportion roles for the students' development and sports teaching quality in universities, and can further promote the development of education cause in China. This paper is mainly targeted at the contents of sunshine sports education in China and briefly explains and analyzes the influence of sunshine sports on the students' individual physical quality and learning development etc.

The competition in the 21st century is the competition of comprehensive strength and also talents. The cultivation of talents depends on education, while education is the footstone to prosper the nationals. In the overall trend of socialist modernization construction, talents of all-round development in moral, intellectual, physical are needed. In 2010, the Ministry of Education, General Administration of Sport, together with other 6 ministries and commissions jointly issued Investigation Result on Student Physical Strength and Health Nationwide in 2010, pointing out that during the 5 years in the implementation of sunshine sports, the physical quality of the beneficiaries of basic education, the primary and middle school students had been improved. However, the physical quality of the higher education has declined continuously, most of the students play games, watch TV in dormitory and seldom participate in the sports training, therefore, the combination of university sports class with sunshine sports has become a problem urgent to be solved.
\end{abstract}

\section{Main contents of university sports class and sunshine sports}

The university sports class is mainly focused on the students' physical strength and comprehensive development. Although the sports class is not to teach the teachers' knowledge interpretation in class like the theoretical classes, it is also an important common compulsory class. The main teaching purpose of sports class is to exercise the students' willpower and exercise and cultivate physical strength of students through the scientific sports structure and means. This class stresses that students can meet the corresponding objective with body building as the form and means and only through repeated scientific training.

Sunshine sports is an education concept proposed by the Ministry of Education according to the trend that the physical quality of the present university students declines continuously. With rich connotation of spiritual culture, it is a sports activity with body exercise as the main form and carried out with the guidance and help of sports teachers by virtue of various sports venues and equipment in campuses. The purpose of carrying out sunshine sports in universities is not to simply exercise the students and guarantee the students' physical strength, but its deeper pursuit is to cultivate the university students to form a good psychological quality and grow healthily. Its main purpose is to continuously improve people's physical quality whole improving endurance and willpower through body training and exercise.

In the university sports class, the sunshine sports require that the teacher should not only be limited to the class, but more importantly, to integrate the class teaching with ex-curricular class, internalize body building into a habit of students, help and guide students to form a good habit, carry out frequent and conscious training and activity and improve the students' physical and psychological health, only the habitual proceeding of this activity can maintain and promote the development of students themselves for a long time. 


\section{Factors influencing the implementation of sunshine sports}

(I) External factor

The current society is a society of talent competition, the fierce competition makes more parents and schools emphasize the students' scores while ignoring their physical exercise, and the ideological concept of "paying more attention to learning while less to sports" has become a mainstream idea in the education of the current society. Under the influence of such concept, and under the current pressure and challenge that China is a large-population country, because of unbalanced development of regional economy, the development of education resources is also influenced, while there is stress in development. Meanwhile, there is a great employment pressure currently, so the quality-oriented education has become an impassable barrier and threshold in the education system of China.

Whether at home or at school, the learning score is used to measure the students' ability and intelligence. The increasing of class burden, expectation of parents, pressure from school make students completely become a machine of learning, with a serious lack of rest and exercise time, and the students' sports class is occupied by other theoretical classes. The long-term lack of sports class causes the parents, schools and other departments as well as the students themselves ignore the sports education, and finally causes that the students are lack of education concept, degrade physical strength and have backward sports cognition and skills in universities.

In addition, due to the rapid development of society, the economic diversification has promoted the cultural diversification, the social production and people's lifestyle have been changed greatly, and people's entertainment and pressure relief methods are also diversified. Therefore, more students ignore the sports class, the routine sports training and exercise, physical training and health, causing the degradation of physical quality. In this situation, it is significantly difficult to carry out sunshine sports.

(II) Internal factors

In the traditional teaching concept, the sports education has always not been emphasized by the university teachers and student parents, the teachers and parents generally think that the students just need to learn the theoretical subjects well, and often ignore and reduce the emphasis on the students' sports scores, which seriously prevents the comprehensive implementation of sports teaching objective in universities and influences the students' exercise and sports. Therefore, the university sports class must be made up necessarily on the basis of serious lack of basic education. It is required to make efforts to improve the students' physical health and improve physical and mental health by applying the scientific sports method, in combination with the actuality and by virtue of certain sports venue and equipment.

It is completely insufficient that the partial sports education concept only relies on the sports courses of universities, because the long-term physical education concept seriously influences the setting of sports courses and presentation form of courses. More importantly, the economic basis determines the superstructure, the major and severe problem faced in the university sports education is difficult to be guaranteed by the fund and time require for the sports activity. In addition, the teachers undertaking the sports class of universities have great and heavy task, who should both complete the sports teaching task assigned by the school, test the students' health and physical strength, but also lead the students to participate in various competitions, and meanwhile, they should also carry out certain scientific research and teaching construction. The university sports teachers have heavy task, but are lack of clear and reasonable labor division, which reduces the sports teaching quality, making it unable to reach the expected teaching effect.

\section{Significance of combining university class with sunshine sports}

(I) Actively create a good and harmonious social atmosphere of concerning the students' physical and mental health and physical quality, pay high attention to sports education in universities, take the comprehensive promotion of quality-oriented education as an important breakthrough and promote the formation of correct talent cultivation concept, so as to promote the 
formation of scientific education and talent concept in the whole society.

The competition in the 21st century is the competition of comprehensive strength among various countries. The talent cultivation strategy of universities require students to have good physical quality and healthy psychological quality, have tolerance and firm willpower and complete the expectation and heavy task of the society and state. Education is the footstone to prosper the national, the students are the hope of national development, only when the young are strong and make progress can the state be strong and make progress. It is the ultimate teaching objective of developing education cause to carry out sunshine sports, apply scientific sports education method, promote the physical strength and students' development, and it is also the reflection of comprehensive strength of China. Sunshine sports activity of actively encouraging students to carry out exercise in various sports venues in and outside universities with education as the breakthrough and starting point and it is to encourage students to walk under the sunshine, enter the nature, cherish the health of their own, the society and nation, and form a good, healthy and scientific and civilized lifestyle and promote their own physical health.

Sunshine sports activity is an inevitable road to take to promote the harmonious and comprehensive development of the Chinese socialism, and its education concept of harmonious creation conforms to the requirements of modern countries and world for the harmonious development and in its development, the education cause of China is improved. Through the sunshine sports activity, the students feel nature in sports exercise, carry out sports exercise in the feeling of nature, and also obtain the physical and mental liberation and upgrading in sports and promote their harmonious development. Meanwhile, it also takes the sports activity as a bridge to establish a good interpersonal relation, create a harmonious, warm and equal environment, so that the students will be in a social environment of harmonious development in daily life, work and learning, continuously enhance their physical strength in the process of development and improve their own quality.

(II) Carry forward sports spirit and cultural connotation with various sports meetings as the opportunity, advocate all-people fitness and improve physical and psychological qualities.

Sports activity is to reflect respective sports gifts and talents amount various sports events with sports as the axis and sports spirit as the condensing point. Carrying forward sports spirit and cultural spirit and encouraging university students and other athletes to pay attention to the daily sports exercise with various sports meetings and competitions as the opportunity can not only improve their physical quality, but more importantly, make them forge their firm willpower and endurance in daily training, more cherish themselves and the opportunity to participate in each competition. Meanwhile, sports activity can also promote the healthy physical and mental development of students, but is also beneficial for the team construction and improves the team quality and efficiency.

\section{Strategy of university sports class to achieve sunshine sports}

(I) Establish and improve the whole-course concept, implement the work of sunshine sports in place, run it through various works of the university sports and make it become a routine sports form.

The teaching practice reform of combining university sports class with the sunshine sports needs to normalize the work. On this basis, the sports universities do not only need to interpret the sports theoretical knowledge, but also introduce the ex-curricular sports intro the daily teaching activity, and appropriately carry out the sports competition activity conforming to the development of students, so that the students can carry out physical competition in spare time of learning, improve their physical quality while cultivating their competition awareness and so as to make the university sports teaching more scientific and systematic, which is beneficial to solve the current situation that the sports class is occupied for a long time and that the students have no opportunity to exercise and train, and also beneficial to improve the situation sunshine sports activity is not implemented in place. The combination of university sports activity with sunshine sports should be normal and systematic, only in this way will it be possible to achieve the objective of improving physical 
strength and changing the situation that the physical quality of the contemporary students is declined.

(II) Explore and innovate the course mode, analyze the specific problem specifically, promote the balanced development of sunshine sports in fitness sports, competition, popularization and improving.

The universities gather students from various places. Because the students are from different regions with difference in education and culture, their individual development situations are different, so is their individual demand. Therefore, the university sports class should pay attention to the development demand of students in different levels, assign the students with more autonomous rights, so that the students can select the targeted sports training according to their personal interest. It is required to respect the students' learning law, master the direction of learning, pay attention to the combination of learning law with learning direction, so as to ensure the parallel development of body building, strengthening physical quality, improving competition ability and popularizing the sunshine sports.

(III) Establish the corresponding evaluation system aimed at the achievements of sports teacher by concerning the national sports education cause, which can promote the effective implementation of university sunshine sports in a certain extent, and play the role of teaching objective examination, teaching achievement feedback, evaluation, adjustment and incentive etc.

In the process of sports education teaching, it is required to conduct detection, evaluation and adjustment continuously, so as to lay a foundation for the further improving of physical spots. This can be started from the following:

(1) Take National Standard for Students' Physical Health as the commanding, and carry out various work according to the document standard, guide the practice method scientifically, combine the class contents with the after-class practice, and actively organize various competition activities; in terms of examination setting, enhance the weight of sports score. Meanwhile, different student groups have different treatment methods. For the students not reaching the standard in examination, carry out targeted guidance, set compulsory guiding courses and form the tracking and supervision system with the improving of students' physical condition as the purpose. When the students' scores reach the standard, incorporate the sports scores in the standard for evaluation for scholarship, so as to improve the students' enthusiasm and activity to participate in the sports.

(2) Establish an objective and fair evaluation system that reflects the students' actual learning condition, combine the students' physical and mental development law and the teaching characteristics of sports education in Chinese universities, and meanwhile include the teaching objective and plan of sports education and timely reflect the students' real learning condition in sports.

(3) In the process of class teaching, incorporate the evaluation of sports class as an important link. Adopt various evaluation methods and more evaluation subjects for assessment and to stimulate the students' participation as the subject, so as to stimulate their potential creative thinking.

The modern quality-oriented education emphasizes the students as the subject. Therefore, while designing the sports course system, it is required to actively play the students' incentive and enthusiasm, improve the students' high participation, only in this way can the students to developed comprehensively.

\section{Conclusion}

The teaching reform practice of combining university sports class with the sunshine sports has an active role in the modern university sports education, improving the students' physical quality and exercising their psychological quality. Therefore, it is required to endeavor and innovate continuously in the ever-changing trend of social reform, so as to promote the development of students better. 


\section{Acknowledgments}

This paper is a president funded project of Qingdao Institute of Technology, project number: 2013JY027

\section{References}

[1] Ministry of Education, General State Administration of Sport Central Committee of the Communist Young League, Education, Sports, Art [2006] No. 6 Document, Decision on Sunshine Sports among Hundreds of Millions of Students Nationwide [R] General Office of the Ministry of Education, 2006

[2] Liu Peng, Speech in report of school sports work meeting nationwide [R] General Office of the State Council, 2006.

[3] CPC Central Committee, State Council, Opinion on Strengthening Sports of Youths and Enhancing their Physical Quality [R], Z.F. [2007] No. 7, May 7, 2007

[4] Wang Caiping, Research on Factors Influencing Sunshine Sports among University Students in Shanxi, Journal of Shanxi University of Finance and Economics, 2010, 32 (1): 230-231.

[5] Wang Shengchao, Research on Characteristics of Sports and Leisure Activities of Ordinary University Students [J], Journal of Beijing Sport University, 2011, 34 (7): 106-110 